
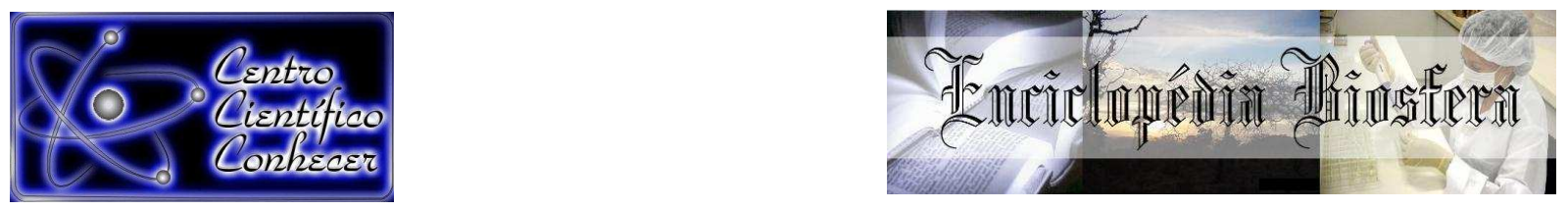

\title{
DESEMPENHO FISIOLÓGICO E QUALIDADE SANITÁRIA DE SEMENTES DE ABÓBORA SEM TRATAMENTO
}

\footnotetext{
Vanessa Nogueira Soares ${ }^{1}$, Daniele Brandstetter Rodrigues ${ }^{2 *}$, Thaís D'Avila Rosa ${ }^{2}$, Jonas Albandes Gularte ${ }^{3}$, Gustavo Fonseca Rodrigues ${ }^{3}$
}

1 Pós Doutoranda do PPG Ciência e Tecnologia de Sementes, da Universidade Federal de Pelotas, Pelotas, RS-Brasil

2 Doutorandas do PPG Ciência e Tecnologia de Sementes, da Universidade Federal de

Pelotas, *(ufpelbrandstetter@hotmail.com), Pelotas, RS-Brasil

3 Graduandos da Faculdade de Agronomia Eliseu Maciel, Universidade Federal de

Pelotas, Pelotas, RS-Brasil

Recebido em: 08/04/2016 - Aprovado em: 30/05/2016 - Publicado em: 20/06/2016 DOI: 10.18677/Enciclopedia_Biosfera_2016_039

\begin{abstract}
RESUMO
Objetivou-se avaliar o desempenho fisiológico e a qualidade sanitária de sementes de abóbora sem tratamento comercializadas no sul do Rio Grande do Sul. Foram utilizados quatro lotes de sementes de abóbora (Cucurbita moschata), cultivar Goianinha, não tratadas. Quanto ao desempenho fisiológico foram realizados os seguintes testes: Emergência de plântulas em casa de vegetação, índice de velocidade de emergência (IVE), germinação, primeira contagem da germinação, envelhecimento acelerado e condutividade elétrica. Para a avaliação da qualidade sanitária foi realizado a incubação das sementes em substrato de papel. Foi utilizado um delineamento experimental inteiramente casualizado com quatro lotes e cinco repetições. As sementes de abóbora cultivar Goianinha, sem tratamento, apresentam percentuais de germinação dentro do padrão de comercialização. No que se refere à incidência de fungos, os seguintes gêneros foram detectados: Alternaria sp., Aspergillus sp., Penicillium sp., Nigrospora sp., e em maior quantidade Rhizopus sp..
\end{abstract}

PALAVRAS CHAVE: Cucurbita moschata, fungos, patógenos.

\section{PHYSIOLOGICAL PERFORMANCE AND HEALTH QUALITY OF PUMPKIN SEEDS WITHOUT TREATMENT}

\begin{abstract}
The aim of this study was to evaluate the physiological performance and the health quality of pumpkin seeds untreated marketed in southern Rio Grande do Sul. We used four lots of pumpkin seeds (Cucurbita moschata) cultivar Goianinha, untreated. Regarding the physiological performance the following tests were performed: Seedling ENCICLOPÉDIA BIOSFERA, Centro Científico Conhecer-Goiânia, v.13 n.23; p. 4422016
\end{abstract}


emergence in the greenhouse, emergency speed index (IVE), germination, first count germination, accelerated aging and electrical conductivity. For evaluation of quality was performed sanitary incubation in a paper substrate. a completely randomized design with four lots and five replications was used. Pumpkin seeds cultivar Goianinha untreated, have germination rates within the standard commercial. As regards the incidence of fungi, the following genera were found: Alternaria sp, Aspergillus sp., Penicillium sp., Nigrospora sp., and in greater quantity Rhizopus sp..

KEYWORDS: Cucurbita moschata, fungi, pathogens.

\section{INTRODUÇÃO}

As Cucurbitáceas apresentam-se em destaque dentre as culturas oleráceas tropicais, pois seus produtos são de ampla aceitação pelos consumidores. Esta família abrange várias espécies como: melão, melancia, pepino e a abóbora. A abóbora em específico apresenta como característica crescimento rasteiro ou trepador, além de ser uma planta herbácea. Seus frutos variam em forma, coloração interna e externa, e ainda com relação ao modo de consumo e tamanho (MARCELINO, 2012).

Atualmente, segundo dados publicados por SOARES et al., 2013, a taxa de uso de sementes certificadas de hortaliças no Brasil é de aproximadamente $100 \%$, porém, a produção nacional de sementes é pequena, sendo a maior parte oriunda de importação. São gastos quase 34 milhões de reais com importação de sementes de hortaliças, sendo aproximadamente um milhão são com sementes de abóbora.

O conhecimento a respeito da qualidade fisiológica e sanitária das sementes a serem utilizadas é de suma importância, pois uma das principais causas da perda ou baixa de viabilidade das sementes é a falta de informação sobre estes atributos (BURIN, 2012). Assim, o sucesso dos cultivos de forma geral pode ser comprometido devido à baixa qualidade fisiológica e sanitária das sementes. Outro fato bastante importante inserido neste contexto é a ocorrência de transmissão de patógenos via sementes, o que pode prejudicar posteriormente as plântulas ou as plantas em desenvolvimento, comprometendo assim a instalação e o estabelecimento da cultura (ARAÚJO, 2013).

Levando em consideração que a germinação, vigor, e identificação da ocorrência de patógenos em sementes têm reflexos no desempenho da plântula, e, portanto, no desempenho da cultura, objetivou-se avaliar o desempenho fisiológico e a qualidade sanitária de sementes de abóbora sem tratamento comercializado no sul do Rio Grande do Sul.

\section{MATERIAL E MÉTODOS}

As sementes adquiridas foram da cultivar Goianinha, da marca ISLA, pois foi a que apresentava maior número de lotes de sementes sem tratamento a venda no munícipio de Pelotas-RS.

Avaliação do Potencial Fisiológico

ENCICLOPÉDIA BIOSFERA, Centro Científico Conhecer - Goiânia, v.13 n.23; p. 443 
Teor de água: determinado pelo método de estufa a $105^{\circ} \mathrm{C}$ por 24 horas. Sendo utilizadas duas subamostras de $4,5 \mathrm{~g}$ de sementes inteiras, segundo as Regras para Análise de Sementes (BRASIL, 2009). Emergência de plântulas em casa de vegetação: realizada com cinco repetições de 100 sementes por lote. A semeadura foi realizada na profundidade de $2 \mathrm{~cm}$, em bandejas com células individualizadas contendo areia lavada e peneirada como substrato (BRASIL, 2009). A avaliação foi realizada oito dias após a semeadura (DAS) por meio da determinação do percentual de emergência de plântulas (NAKAGAWA, 1994). Considerou-se como plântula emergida aquelas com altura mínima de meio centímetro.

Índice de velocidade de emergência (IVE): executado conjuntamente com o teste de emergência, sendo as avaliações realizadas diariamente até o décimo quarto DAS e o IVE calculado conforme proposta de MAGUIRE (1962).

Teste de germinação: conduzido em substrato papel, com quatro subamostras de 50 sementes para cada repetição, de cada lote. As sementes foram colocadas para germinar entre três folhas de papel germitest previamente umedecidos com uma quantidade de água destilada equivalente a 2,5 vezes a massa do substrato seco, as folhas de papel contendo as sementes foram embrulhados em forma de rolos e colocados no germinador em posição vertical a temperatura de $25^{\circ} \mathrm{C}$. As avaliações foram realizadas aos quatro e aos oito DAS e os resultados expressos em porcentagem de plântulas normais e anormais e sementes mortas (BRASIL, 2009).

Primeira contagem da germinação: efetuada em conjunto com o teste de germinação, computando-se a porcentagem de plântulas normais obtidas no quarto DAS (BRASIL, 2009).

Envelhecimento acelerado: foram utilizadas 200 sementes por repetição de cada lote, subdivididas em quatro subamostras de 50 sementes. Posteriormente, as subamostras foram distribuídas sobre tela de alumínio fixada no interior de caixa plástica (minicâmara) contendo $40 \mathrm{~mL}$ de água destilada e mantidas por 48 horas a temperatura de $41^{\circ} \mathrm{C}$ (MALONE et al., 2008). Decorrid o este período, foi determinado o teor de água das sementes e conduzido o teste de germinação seguindo a metodologia descrita para essa espécie na RAS (BRASIL, 2009). A avaliação das plântulas foi realizada aos quatro dias após a semeadura, computando-se a porcentagem de plântulas normais e anormais e sementes mortas.

Condutividade elétrica (CE): conduzido pelo método de massa, com quatro subamostras de 50 sementes da porção sementes puras de cada lote e pesadas com precisão de quatro casas decimais $(0,0001 \mathrm{~g})$ para cada repetição, de cada lote. Em seguida, as sementes foram colocadas em copos plásticos contendo $75 \mathrm{~mL}$ de água (VIEIRA e DUTRA, 2006) deionizada e mantidas em câmara de germinação, tipo BOD, na temperatura de $25^{\circ} \mathrm{C}$, por 24 horas de embebição. Após esse período, a CE da solução foi determinada por meio do condutivímetro DIGIMED ${ }^{\circledR}$, modelo 32 e os resultados expressos em $\mu \mathrm{S} . \mathrm{cm}^{-1} \cdot \mathrm{g}^{-1}$ de sementes. A leitura da CE foi realizada logo após a retirada do material da incubadora, de modo gradativo, agitando-se cuidadosamente cada recipiente, com o intuito de uniformizar os eletrólitos lixiviados na solução.

Qualidade sanitária 
Incubação em substrato de papel: Foram utilizadas cinco repetições, cada uma constando de oito caixas tipo gerbox com 25 sementes dispostas sobre um papel filtro umedecido com água destilada. Posteriormente, as caixas contendo as sementes foram mantidas em câmara de incubação a $20 \pm 2^{\circ} \mathrm{C}$, por se te dias em regime intermitente de $12 \mathrm{~h}$ de luz e $12 \mathrm{~h}$ de escuro. Para a identificação das estruturas dos patógenos foi utilizado um microscópio estereoscópico e microscópio biológico, segundo as Regras para Análise de Sementes (BRASIL,2009).

\section{Análise estatística}

Foi utilizado um delineamento experimental inteiramente casualizado com quatro lotes e cinco repetições. Os dados expressos em percentagem foram transformados em arcsen $(\sqrt{ } \times \div 100)$ e, posteriormente, submetidos a análise de variância (ANOVA), e as médias comparadas pelo teste de Tukey $(p<0,05)$.

\section{RESULTADOS E DISCUSSÃO}

Pode ser observado que o teor de água nos lotes 2, 3 e 4 obtiveram percentuais semelhantes diferindo apenas do lote 1 das sementes de abóbora (Tabela 1). A determinação do teor de água em um lote de sementes é de suma importância, pois influencia aspectos tanto sobre a qualidade fisiológica, como também a melhor adequação para seu armazenamento (SILVA, 2015). Embora a diferença do grau de umidade de até $2 \%$ entre os lotes de sementes avaliados, não seja uma porcentagem temerária, a sua avaliação é recomendada.

TABELA 1- Teor de água (TA), plântulas normais (PN), anormais (PA) e sementes mortas (SM) nos testes de germinação e envelhecimento acelerado (EA) e de teor de água após envelhecimento acelerado (TAAEA) em lotes de sementes de abóbora.

\begin{tabular}{ccccccccc}
\hline & \multirow{2}{*}{ Lote } & TA & \multicolumn{4}{c}{ Germinação (\%) } \\
\cline { 3 - 9 } & $(\%)$ & PN & PA & SM & PN & PA & SM & $\begin{array}{c}\text { TA após } \\
\text { EA (\%) }\end{array}$ \\
\hline 1 & 6,7 & $79 \pm 1,96 \mathrm{~b}$ & $12 \pm 1,50 \mathrm{~b}$ & $9 \pm 1,16 \mathrm{c}$ & $78 \pm 1,53 \mathrm{ab}$ & $12 \pm 1,20 \mathrm{a}$ & $10 \pm 1,65 \mathrm{ab}$ & 24,7 \\
2 & 7,1 & $92 \pm 0,98 \mathrm{a}$ & $4 \pm 1,34 \mathrm{a}$ & $4 \pm 0,81 \mathrm{a}$ & $86 \pm 2,00 \mathrm{a}$ & $9 \pm 1,93 \mathrm{a}$ & $5 \pm 0,20 \mathrm{a}$ & 25,0 \\
3 & 7,4 & $81 \pm 1,20 \mathrm{~b}$ & $11 \pm 1,59 \mathrm{~b}$ & $8 \pm 0,73 \mathrm{bc}$ & $74 \pm 3,81 \mathrm{~b}$ & $13 \pm 1,71 \mathrm{a}$ & $12 \pm 2,42 \mathrm{~b}$ & 25,3 \\
4 & 7,3 & $92 \pm 1,17 \mathrm{a}$ & $4 \pm 0,71 \mathrm{a}$ & $4 \pm 0,87 \mathrm{a}$ & $76 \pm 2,71 \mathrm{~b}$ & $17 \pm 2,71 \mathrm{a}$ & $7 \pm 1,77 \mathrm{ab}$ & 23,5 \\
\hline
\end{tabular}

${ }^{1}$ Médias seguidas pela mesma letra na coluna não diferem entre si pelo teste de Tukey $(p<0,05)$.

Para a porcentagem de germinação dos lotes de sementes de abóbora (Tabela 1), todos os lotes apresentaram germinação mínima de $80 \%$ exigida para a comercialização de sementes da espécie. Foi verificado que o lote 1 e 3 não diferiram estatisticamente nas determinações de plântulas normais, anormais e sementes mortas 
no teste de germinação, pode ser observado que os lotes 2 e 4 tiveram comportamento semelhante não diferindo entre si, para as mesmas determinações.

Em relação ao teste de envelhecimento acelerado, que é um dos testes mais utilizados para avaliar o desempenho fisiológico de sementes, nota-se (Tabela 1) que o lote 4 apresentou $92 \%$ de germinação, obteve $76 \%$ na avaliação das plântulas normais após o envelhecimento acelerado, não diferindo dos lotes 1 e 3 que apresentaram menor germinação. Ou seja, apesar de apresentar percentual de germinação superior a esses lotes, o lote 4 não diferiu no vigor dos lotes com menor germinação.

Cabe salientar nesse contexto, que o lote 2 mesmo não diferenciando do lote 1 , apresentou em porcentagem, superioridade dos demais lotes. Para a avaliação das plântulas anormais, não houve diferença entre os lotes, e para a avaliação de sementes mortas o lote 1 não diferiu dos lotes 2,3 e 4. Pode-se verificar que o lote 2 apresentou baixa porcentagem de sementes mortas, ratificando seu resultado no teste de vigor.

Os testes de vigor são empregados para distinguir os diferentes níveis de vigor entre as sementes, podendo ser utilizados também para diferenciar diferentes lotes. Estes testes podem ser de dois tipos: os métodos diretos e indiretos. Os diretos buscam simular as condições, inclusive as antagônicas que ocorrem no campo, já os métodos indiretos procuram aferir características que indiretamente se incluem com vigor como os físicos e biológicos das sementes (MATTIONI, 2012).

O resultado de vigor das sementes de abóbora, pela determinação da primeira contagem de germinação e emergência de plântulas, foi semelhante entre os lotes avaliados, conforme ocorreu para as variáveis do teste de germinação. O mesmo comportamento ocorre nos testes do índice de velocidade de emergência e condutividade elétrica, onde, o lote 2 e 4 destacaram-se por apresentar qualidade superior aos demais (Tabela 2).

Contudo, não constam nas Regras para Análise de Sementes (BRASIL, 2009) e tampouco na ISTA (Iternacional Seed Testing Association) e na AOSA (Association of Official Seed Analysts) testes de vigor para sementes de abóbora com a finalidade de classificar quanto ao nível de vigor. A existência de um teste padronizado para avaliação de vigor em sementes de abóbora, como ocorre no caso de sementes de ervilha em que a determinação da condutividade elétrica da solução de embebição da semente, adequa-se como teste de vigor (AOSA, 2002). Tal teste poderia atender a demanda de empresas produtoras de sementes, que muitas vezes sentem dificuldade no posicionamento de lotes de sementes para a comercialização. Na situação atual, mesmo que lotes de sementes de abóbora apresentem baixo vigor por algum teste realizado, mas atenderem ao limite mínimo de germinação e pureza estabelecido pelo Ministério da Agricultura do Brasil, podem ser comercializados, mesmo que isso represente problemas de emergência de plântulas no campo e o estabelecimento inicial da cultura. 
TABELA 2- Primeira contagem da germinação (PCG), emergência (E), índice de velocidade de emergência (IVE) e condutividade elétrica (CE) de lotes de sementes de abóbora.

\begin{tabular}{ccccc}
\hline Lote & PCG $(\%)$ & E (\%) & IVE & CE $(\mu \mathrm{S} / \mathrm{cm} / \mathrm{g})$ \\
\hline 1 & $72 \pm 2,99 \mathrm{~b}$ & $57 \pm 1,50 \mathrm{~b}$ & $8,76 \pm 0,30 \mathrm{~b}$ & $100,71 \pm 1,69 \mathrm{~b}$ \\
2 & $87 \pm 1,24 \mathrm{a}$ & $79 \pm 2,17 \mathrm{a}$ & $12,04 \pm 0,45 \mathrm{a}$ & $53,41 \pm 1,70 \mathrm{a}$ \\
3 & $73 \pm 1,07 \mathrm{~b}$ & $50 \pm 2,11 \mathrm{~b}$ & $6,08 \pm 0,16 \mathrm{c}$ & $110,56 \pm 3,27 \mathrm{c}$ \\
4 & $89 \pm 1,29 \mathrm{a}$ & $74 \pm 4,85 \mathrm{a}$ & $12,30 \pm 0,25 \mathrm{a}$ & $54,73 \pm 1,06 \mathrm{a}$ \\
\hline
\end{tabular}

${ }^{1}$ Médias seguidas pela mesma letra na coluna não diferem entre si pelo teste de Tukey a $5 \%$ de probabilidade de erro.

A propagação da cultura da abóbora se dá, sobretudo por sementes, logo a qualidade sanitária destas é fator de grande importância a sua produção, pois sementes contaminadas estabelecem importante veículo de dispersão de patógenos, dentre os quais se destacam os fungos (CARVALHO, 2014). De maneira geral, as sementes podem se tornar abrigo e transportar microrganismos de todos os grupos taxonômicos, patogênicos ou não; por isso a detecção desses organismos torna-se um dos mais importantes instrumentos no manejo fitossanitário de doenças (FANTINEL, 2015).

Neste sentido, a alta incidência de fungos associados às sementes causa danos consideráveis, especialmente em cucurbitáceas ocasionando perdas totais da produção (SOARES et al., 2016). De acordo com os dados observados, pode-se inferir que houve incidência de fungos em todos os lotes de sementes de abóbora, com destaque para o fungo Rhizopus sp.

O lote 3 foi o que apresentou a maior incidência em comparação aos outros lotes. Quanto ao fungo Nigrosposra sp. observou-se que este foi mais incidente nos lotes $1 \mathrm{e}$ 3 , não diferindo dos demais lotes avaliados. Para os fungos Alternaria sp., Aspergillus sp. e Penicillium sp. os lotes não diferiram entre si (Tabela 3).

Quanto ao tratamento de sementes, atualmente o uso de produtos químicos é o método mais utilizado, embora agregue elevados custos e riscos ambientais (CAMPANHOLA \& BETTIOL, 2003). A viabilidade de tratamentos alternativos tem sido investigada, especialmente àqueles à base de extratos vegetais, controle biológico ou tratamento físico, pois possuem como vantagem a redução de gastos para o produtor e ausência de impacto ambiental causado pelos agroquímicos (COUTINHO et al., 1999). 
TABELA 3- Incidência (\%) de fungos em lotes de sementes de abóbora.

\begin{tabular}{cccccc}
\hline Lote & Alternaria sp. & $\begin{array}{c}\text { Aspergillus } \\
\text { sp. }\end{array}$ & $\begin{array}{c}\text { Penicillium } \\
\text { sp. }\end{array}$ & Nigrospora sp. & Rhizopus sp. \\
\hline 1 & $2,90 \pm 1,32 \mathrm{a}$ & $5,00 \pm 0,93 \mathrm{a}$ & $3,00 \pm 1,48 \mathrm{a}$ & $8,00 \pm 1,97 \mathrm{a}$ & $13,60 \pm 1,72 \mathrm{ab}$ \\
2 & $2,20 \pm 0,96 \mathrm{a}$ & $5,00 \pm 2,79 \mathrm{a}$ & $2,00 \pm 1,29 \mathrm{a}$ & $0,40 \pm 0,24 \mathrm{~b}$ & $12,00 \pm 1,23 \mathrm{~b}$ \\
3 & $2,00 \pm 0,75 \mathrm{a}$ & $5,00 \pm 0,96 \mathrm{a}$ & $7,00 \pm 2,90 \mathrm{a}$ & $5,20 \pm 2,46 \mathrm{ab}$ & $19,6 \pm 2,55 \mathrm{a}$ \\
4 & $2,00 \pm 0,00 \mathrm{a}$ & $6,00 \pm 0,75 \mathrm{a}$ & $2,00 \pm 0,49 \mathrm{a}$ & $0,50 \pm 0,27 \mathrm{~b}$ & $13,10 \pm 0,68 \mathrm{ab}$
\end{tabular}

${ }^{1}$ Médias seguidas pela mesma letra na coluna não diferem entre si pelo teste de Tukey $(p<0,05)$.

Segundo SOUSA (2014), avaliando o tratamento e qualidade de sementes de abóbora, observou a incidência de diversos fungos, incluindo os encontrados no presente trabalho, mesmo quando as sementes receberam o tratamento fungicida.

\section{CONCLUSÕES}

As sementes de abóbora cultivar Goianinha, sem tratamento, apresentam percentuais de germinação dentro do padrão de comercialização.

No que se refere à incidência de fungos, os seguintes gêneros foram detectados: Alternaria sp., Aspergillus sp., Penicillium sp., Nigrospora sp., e em maior quantidade Rhizopus sp.

\section{REFERÊNCIAS}

ARAÚJO, E. R.; ANDRADE, L. A.; RÊGO, E. R.; GONÇALVES, E. P.; ARAÚJO, E. Qualidade fisiológica e sanitária de sementes de aroeira produzidas no estado da Paraíba. Agropecuária Técnica. v. 34, p. 9-20, 2013.

ASSOCIATION OF OFFICIAL SEED ANALYSTS. Seed Vigor Testing Handbook. Lincoln. 2002. 105p. (Contribution 32).

BRASIL. Ministério da Agricultura, Pecuária e Abastecimento. Regras para análise de sementes. Ministério da Agricultura, Pecuária e Abastecimento. Secretaria de Defesa Agropecuária. Brasília: MAPA/ACS, 2009. Disponível em: < $<395$ p.http://www.agricultura.gov.br/arq_editor/file/Laborat\%C3\%B3rio/Sementes/Regra s\%20para\%20Analise\%20de\%20Sementes.pdf >

BURIN, C. C. Potencial de utilização e incentivos do uso de sementes de qualidade de hortaliças do município de Cassilândia-MS. In... Anais do Seminário de Extensão 
Universitária, SEMEX, Dourados, MT, ANAIS, 2012. Disponível em: <anaisonline.uems.br/index.php/semex/article/view/598>

CARVALHO, D. D. C., OLIVEIRA, A. M. E., LAGO, H., MARIA, D. S., \& RODRIGUES, F. Incidência de Bipolaris bicolor em sementes de sorgo granífero no brasil. Revista Brasileira de Milho e Sorgo, v.13, n.2, p.240-247, 2014.

CAMPANHOLA, C.; BETTIOL, W. Panorama sobre o uso de agrotóxicos no Brasil. In: CAMPANHOLA, C.; BETTIOL, W. Métodos alternativos de controle fitossanitário. Jaguariúna: Embrapa Meio Ambiente, 2003. p. 13-50.

COUTINHO, W.M.; ARAÚJO, E.; MAGALHÃES, F.H.L. Efeitos de extratos de plantas anacardiáceas e dos fungicidas químicos benomyl e captan sobre a microflora e qualidade fisiológica de sementes de feijoeiro (Phaseolus vulgaris L.). Ciência e Agrotecnologia, v. 23, n. 3, p. 560-568, 1999.

FANTINEL, V. S.; OLIVEIRA, L. M.; CASA, R. T.; DA ROCHA, E. C.; SCHENEIDER, P. F.; VICENTE, D. Tratamento de sementes de goiaba-serrana (Acca sellowiana): efeito na incidência de fungos e na germinação. Revista Brasileira de Biociências, v. 13, n.2, p. 84-89 2015.

MAGUIRE, J.B. Speed of germination-aid in selection and evaluation for seedling emergence vigor. Crop Science, v.2, n.2, p.176-177, 1962.

MALONE, P.F.V.A.; VILELLA, F.A.; MAUCH, C.R. Potencial fisiológico de sementes de mogango e desempenho das plantas no campo. Revista Brasileira de Sementes, v.30, n.2, p.123-120, 2008. Disponível em: <http://www.scielo.br/scielo.php?pid=S010131222008000200015\&script=sci_abstract\&tlng=pt>. doi: 10.1590/S0101$31222010000300015>$

MARCELINO, J.S., MARCELINO, M.S., Cultivo de abóboras. Dossiê Técnico, Instituto de Tecnologia do Paraná. 2012. Disponível em: <http://www.sbrt.ibict.br/dossietecnico/downloadsDT/NjExOA==>

MATTIONI, F., ALBUQUERQUE, M. C. F., MARCOS-FILHO, J., GUIMARÃES, C. S. Vigor de sementes e desempenho agronômico de plantas de algodão. Revista Brasileira de Sementes, v. 34, n.1, p. 108-116, 2012. Disponível em: <http://dx.doi.org/10.1590/S0101-31222012000100014 > doi: 10.1590/S010131222012000100014>

NAKAGAWA, J. Testes de vigor baseados na avaliação das plântulas. In: VIEIRA, R. D.; CARVALHO, N. M. (Ed.). Testes de vigor de sementes. Jaboticabal: Funep, 1994. p. 49-85. 
SARMENTO, H. G., DE SOUZA DAVID, A. M. S., BARBOSA, M. G., NOBRE, D. A. C., \& AMARO, H. T. R. Determinação do teor de água em sementes de milho, feijão e pinhão-manso por métodos alternativos. Energia na agricultura, v.30, n.3, p.250-256, 2015. Disponível em: < http://dx.doi.org/10.17224/EnergAgric.2015v30n3p250-256> . doi: 10.17224/EnergAgric.2015v30n3p250-256.

SOARES, D. C. P. Cultivo orgânico de hortaliças: cuidados da obtenção da semente até a comercialização dos produtos. Agropecuária Científica no Semiarido, v.9, n.2, p.0113, 2013.

SOARES, M. G. O.; SOARES, J. A. ; CEZAR, M. A.; CARDOSO, T. A. L.; LIMA, J. A. A. Ocorrência de patógenos em cultivos de melancia e abóbora no sertão da Paraíba. Revista Verde de Agroecologia e Desenvolvimento Sustentável, v. 11, p. 07-13, 2016.

SOUSA, M. C. F., SILVA, C. F., OLIVEIRA, C. J., NETTO, C. G., PINHEIRO, L. M. C. Tratamento e qualidade de sementes de abóbora armazenadas. Tratamento e qualidade de sementes de abóbora armazenadas. In... Anais do Salão Internacional de Ensino, Pesquisa e Extensão, SIEPE, Unipampa, Bagé, RS, ANAIS, 2000. Disponível em: <http://publicase.unipampa.edu.br/index.php/siepe/article/view/8153>

VIEIRA, R. D.; DUTRA, A. S. Condutividade elétrica em sementes de abóbora, híbrido Bárbara. Horticultura Brasileira. v. 24, p. 305-308, 2006. 